\title{
Ear temperature and brain blood flow: Laterality effects
}

\author{
MARY LEE MEINERS and JAMES M. DABBS, JR. \\ Georgia State University, Atlanta, Georgia 30303
}

Temperature at the tympanic membrane (eardrum) provides an indirect measure of cerebral blood flow. Decreases in temperature, reflecting increases in blood flow, appear during performance of mental tasks. Decreases are greater in the left ear during verbal tasks and in the right ear during spatial tasks. Tympanic temperature may provide a simple and flexible measure of mental functioning under a variety of conditions.

Mental activity depends upon metabolism in the brain. Because blood brings the oxygen needed for metabolism, and blood flow affects temperature, temperature might provide an index of mental activity. We have found that verbal and spatial tasks affect temperature differently on the two sides of the brain.

Two physiological techniques for monitoring brain activity have been widely employed. Measures of EEG activity detect overall brain activity as well as regional differences within the brain (Kimura, 1973). Measures of blood flow also can reveal areas of localized metabolic activity within the brain. Blood flow to the brain is controlled largely by local $\mathrm{CO}_{2}$ pressure, with the capillaries dilating and blood flow increasing when $\mathrm{CO}_{2}$ pressure increases (Guyton, 1971; Kety, 1958). Studies with sacrificed animals show more blood has gone to regions of the brain most recently in use (Bondy, Lehman, \& Purdy, 1974). With human beings xenon can be inhaled or injected and taken up in the blood; scintillation counters around the head then show concentration of xenon in areas of the brain currently in use (Ingvar \& Schwartz, 1974; Risberg, Halsey, Wills, \& Wilson, 1975). EEG and blood flow techniques of monitoring brain activity are cumbersome, expensive, and at best restrictive or at worst dangerous to the subject. They are "reactive": the subject can hardly behave normally while such monitoring is going on.

In the present experiment we used a simple measure of temperature to detect changes in blood flow. Brain temperature reflects blood temperature to some extent, changing as the temperature of the blood throughout the body changes (Hayward \& Baker, 1969). But brain temperature also reflects amount of blood flow, because blood cools the brain (Minard \& Copman, 1963; Serota \& Gerard, 1938), and there is an inverse relationship between blood flow and brain temperature. Blood flow can change rapidly, and brain temperature will

This research was supported in part by NIMH Grant 5 R01 MH20660 and NSF Grant BNS76-17403. Requests for reprints should be sent to James M. Dabbs, Jr., Department of Psychology, Georgia State University, Atlanta, Georgia 30303. rise and fall as blood flow decreases and increases (Aschoff, Aschoff, \& von Saint Paul, 1973).

We monitored temperature at the tympanic membrane (eardrum). The tympanic membrane is warmed by the brain and cooled by blood from branches of the carotid artery; its temperature is highly correlated with temperature at the hypothalamus (Benzinger, 1969; Dickey, Ahlgren, \& Stephen, 1970; Rawson \& Hammell, 1963). The technique we used is simple and harmless. The subject placed a small and pliable plastic-covered thermocouple in his or her ear, and temperature was recorded instantaneously and automatically. We expected to find tympanic temperature decreasing under conditions in which blood flow is known to increase.

Because the experiment was set up to explore temperature as a measure of blood flow, we needed test conditions known to affect blood flow. These conditions are met by the laterality paradigm. Different kinds of mental tasks tend to be performed on different sides of the brain (e.g., verbal tasks on the left and spatial tasks on the right) (Dimond \& Beaumont, 1974). Risberg et al. (1975), using xenon inhalation techniques, found blood flow increasing to both sides of the brain while subjects performed mental tasks, but increasing more to the left with verbal tasks and more to the right with spatial tasks. In the present experiment we monitored temperature in the left and right ears while subjects performed verbal and spatial tasks, the expectation being that temperature would drop more (indicating more blood flow) in the left ear during verbal tasks and in the right ear during spatial tasks.

\section{METHOD}

Subjects were 20 right-handed college students, 11 female and 9 male. Each subject inserted a pliable thermocouple probe of about $.8-\mathrm{mm}$ diam into each ear until it rested upon or near the eardrum. Proper positioning of the probe was assumed when temperature readings became steady at approximately $37^{\circ} \mathrm{C}$. Each probe was connected by a 6-ft lead to a battery-powered thermometer, which in turn was connected to a two-channel chart recorder. ${ }^{1}$

Tasks similar to those used by Risberg et al. (1975) were selected. ${ }^{2}$ The left brain task was a selection of analogies from a 
study guide for the Miller Analogies Test (Turner, 1973). Analogies were selected which were relatively easy and which, in the opinion of eight graduate students, did not require much visualization to solve. The right brain task consisted of items selected from the spatial ability subtest of the Differential Aptitude Test (Bennet, Seashore, \& Wesman, 1962).

Prior to insertion of the probes, the experimenter spent several minutes assuring the subject of the safety of the device and explaining the procedure. Subjects were encouraged to concentrate upon the tasks and work as hard as possible. A reward of $\$ 5$ was promised to those subjects whose performance proved to be in the top $20 \%$ of the sample. Risberg et al. (1975) found such an incentive important. Following insertion of the thermocouple probes, the experimenter left the subject alone and moved to an adjoining room, monitoring temperature on the chart recorder there and giving instructions by intercom. The session was divided into five 5-min segments: initial baseline, first task, second baseline, second task, and final baseline. Order of the verbal and spatial tasks was counterbalanced from subject to subject. During the baseline conditions subjects were instructed to relax but keep their eyes open.

\section{RESULTS}

In analyzing the data we first looked to see whether temperature decreased during task performance. Each of the five task and baseline conditions was divided into 1 -min segments, with temperature at the end of each minute scored to the nearest $.005^{\circ} \mathrm{C}$ above or below temperature at the beginning of the condition. For each subject, data from the two task conditions. were combined, as were data from the three baseline conditions, to produce mean temperature scores for the end of each task minute and each baseline minute. The data are summarized in Figure 1.

While the mean pattern shows a smooth decrease during task performance, individual temperatures were erratic and sometimes even increased during a task or baseline. The high variability of individual patterns suggested a nonparametric analysis was appropriate, and we therefore assigned each subject one score for mean temperature during the tasks and another for mean temperature during the baseline. Mean temperature was lower during tasks than during baselines for 15 out of 20 subjects $(\mathrm{p}<.03$ by sign test).

We next looked to see whether temperature decreases

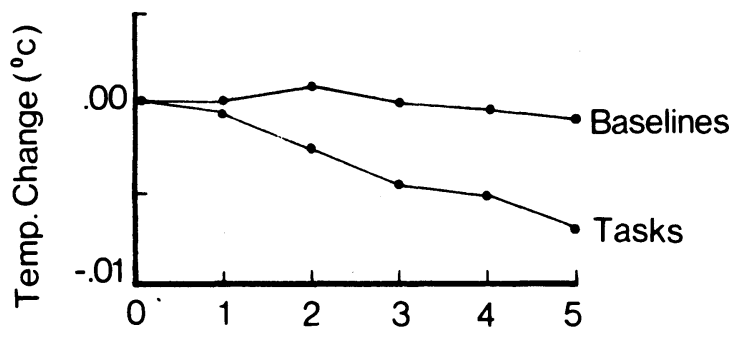

Time (minutes)

Figure 1. Mean temperature during task and baseline conditions.
Table 1

Mean Maximum Decreases in Temperature (Degrees Centigrade) During Task Performance

\begin{tabular}{ccc}
\hline Task & Left Ear & Right Ear \\
\hline Verbal & -.020 & -.020 \\
Spatial & -.010 & -.024 \\
\hline
\end{tabular}

were greater on the "thinking" side of the brain-the left side during verbal tasks and the right side during spatial tasks. A decrease indicates more blood is flowing, which is the behavior we wished to study. We chose to ignore increases in temperature and examine maximum decreases in each condition. All records, no matter how erratic, were scored to show the decrease from the beginning to the lowest point during a 5-min task in a given ear. Zero scores were assigned when there was no decrease (or an increase) during the task period. Mean scores for each task-ear condition are shown in Table 1.

A 2 by 2 (task by ear) within-subjects analysis of variance of these data revealed a significant Task by Ear interaction $[F(1,19)=7.77, p<.05]$. The largest decreases occurred with spatial tasks in the right ear and verbal tasks in the left ear.

\section{DISCUSSION}

Our findings suggest that tympanic temperature can provide a subtle indicator of blood flow. Tympanic temperature will also be affected by environmental temperature and overall body temperature, but here we observed it to decrease while thinking and decrease more on the "thinking" side of the brain, consistent with what is known about blood flow.

The effects studied in the present experiment were small in size. In the narrow range of temperatures we observed, spontaneous increases or decreases were sometimes visible during the baselines. We chose to ignore baseline changes (which averaged out to zero), but other investigators might wish to compare the effects of experimental conditions with expected projections from an increasing or decreasing baseline. Temperature decreases will generally be small, because the incoming arterial blood itself provides a support for temperature which is only a fraction of a degree below the temperature of the brain (Minard \& Copman, 1963). Increases in termperature are not subject to the same limit and are in general much larger (cf. Dabbs \& Moorer, 1975).

Temperature has more than just the appeal of simplicity. Its usefulness as a measure of cerebral blood flow, and therefore of brain activity, extends well beyond the effects reported here. A simple measure of brain activity might help reveal why different situations are more or less important to a person. Temperature can be monitored in laboratories that lack elaborate equipment and monitored on subjects engaged in a variety of tasks. Since conducting this research we have learned that temperature can be measured equally well anywhere in the ear canal, not just at the tympanic membrane. A probe suspended from an earplug can remain comfortably in the ear canal for hours at a time. We are presently beginning to work with telemetry equipment. Temperature telemetry is relatively simple, and with telemetry one can study subjects passing through the varied activities of an ordinary day.

One intriguing set of questions posed by the present research deals with the significance of increases in temperature. We suspect the occasional increases we observed were associated with 
feelings of anxiety and a failure to concentrate, but perhaps they would appear under any conditions of general arousal. Others report that unexpected interaction with a stranger leads to increases in temperature among animals (von Saint Paul \& Aschoff, 1968) and among people (Dabbs \& Moorer, 1975). Using telemetry, we plan to explore further the conditions that cause temperature to increase. Our suspicion now is that increases indicate blood is being diverted from the brain to the rest of the body, as part of a shift from cognitive processing to a more physical activity.

\section{REFERENCES}

Aschoff, C.. Aschoff, J., \& von Saint Paul, U. Circadian rhythms of chicken brain temperatures. Journal of Physiology. 1973, 230, 103-113.

Bennet, G. K., Seashore, H. G., \& Wesman, A. G. Differential aptitude tests. New York: Psychological Corporation, 1962.

Benzinger, T. Clinical temperature. Journal of American Medical Association, 1969, 209, 1200-1206.

Bondy, S. C., Lehman, R. A. W., \& Prudy, J. L. Visual attention affects brain blood flow. Nature, 1974, 248, 440-441.

Dabbs, J. M., JR., \& Moorer, J. P., JR. Core body temperature and arousal. Personality and Social Psychology Bulletin, 1975, 1, 517-520.

Dickey, T., Ahlgren, E. W., \& Stephen, C. R. Body temperature monitoring via the tympanic membrane. Surgery, 1970, 67, 981-984.

Dimond, S. J., \& Beaumont, J. C. (EDs.). Cerebral hemispheric specialization for specialists. New York: Halstead, 1974.

GuYton, A. C. Textbook of medical physiology. Philadelphia: Saunders, 1971.

HAYWARD, J. N., \& BAKER, M. A. A comparative study of the role of the cerebral arterial blood in the regulation of brain temperature in five mammals. Brain Research, 1969, 16, 417-420.
INGVAR, D. H., \& Schwartz, M. S. Blood flow patterns induced in the dominant hemisphere by speech and reading. Brain, 1974, 97, 273-288.

KETY, S. S. The cerebral circulation. In J. McMichael (Ed.), Circulation: Proceedings of the Harvey Tercentenary Congress. Springfield, Ill: Thomas, 1958.

KImURA, D. The asymmetry of the human brain. Scientific American, 1973, 228, 70-80.

MinaRD, D., \& Copman, L. Elevation of body temperature in health. In D. Minard \& L. Copman (Eds.), Temperature: Its measurement and control in science and industry. New York: Reinhold, 1963.

Rawson, R. O., \& Hammell, H. T. Hypothalamic and tympanic membrane temperature in rhesus monkeys. Federation Proceedings. Federation of American Societies for Experimental Biology, 1963, 22, 283.

Risberg, J., Halsey, J. H., Wills, E. L., \& Wilson, E. M. Hemispheric specialization in normal man studied by bilateral measurements of the regional cerebral blood flow. Brain, 1975, 98, 511-524.

Serota, H. M., \& Gerard, R. W. Localized thermal changes in the cat's brain. Journal of Neurophysiology, 1938, 1, 115-124.

TURNER, D. R. Miller analogies test. New York: Arco, 1973.

von SAINT PaUl, U., \& Aschoff, J. Gehirntemperaturen bei Huhnern. Pflugers Archiv, 1968, 301, 109-123.

\section{NOTES}

1. Each thermometer emitted a dc signal of $10 \mathrm{mV} /{ }^{\circ} \mathrm{C}$, with $50 \mathrm{mV}$ equivalent to $37^{\circ} \mathrm{C}$. The chart recorder was set to display $10-\mathrm{mV}$ full-scale deflection in the $40-$ to $50-\mathrm{mV}$ range on each channel. With this scale setting, one gradation on the chart paper $\left(.1 \mathrm{in}\right.$.) represented $.1 \mathrm{mV}$, or $.01^{\circ} \mathrm{C}$.

2. Copies of the task materials are available from the authors.

(Received for publication May 9, 1977.) 